\title{
Educação remota em Tempos de Pandemia da Covid-19: desafios e aprendizados
}

Em dezembro de 2019, em Wuhan na China, tomamos conhecimento do primeiro caso da doença que seria definida como Covid-19, ou doença causada pelo novo coronavírus (SARS-CoV-2). Em março de 2020, a Organização Mundial da Saúde (OMS) declarou a existência de uma pandemia pela Covid-19. Semana após semana, de janeiro a abril, todos os seres humanos viventes no planeta Terra experimentaram os efeitos deste acontecimento monumental, que afetou e continua afetando profundamente a vida das pessoas. Ao longo do ano de 2020, fomos testemunhas da escalada no número de casos e de mortes devido à Covid-19 desde a Ásia, Europa, América do Norte, América do Sul e no Brasil. Somos testemunhas da história e dos impactos que a pandemia causa nas relações interpessoais, oferta de serviços de todas as naturezas, na economia e principalmente na saúde individual e coletiva.

Como seres humanos, professores, profissionais da saúde e da educação os autores dos artigos apresentados neste Simpósio compartilham com os leitores um pouco das vivências, desafios, soluções e caminhos percorridos durante o ano de 2020, no enfrentamento da pandemia da Covid-19, com olhar mais atento para as instituições de ensino superior brasileiras.

A ideia de organizar este Simpósio sobre a Educação Remota em Tempos de Pandemia, nasceu no primeiro semestre de 2020, logo que os editores perceberam a dimensão do que estava acontecendo e a importância de registrar, na medida do possível, o que estava acontecendo. Ao mesmo tempo que todos conviviam com o medo, a sobrecarga de trabalho, as inúmeras incertezas e inclusive perdas, decorrentes do espalhamento de maneira descontrolada do vírus SARS-CoV-2 pela Terra Brasilis acumulava-se conhecimento e experiências sobre como lidar com tudo que acontecia. No momento em que escrevemos este texto, o Brasil acabava de ultrapassar a marca de 270.000 mortes pela Covid-19. Duzentos e setenta mil vidas ceifadas pelo novo vírus, quando o país enfrenta a "segunda onda" da Covid-19, com parcelas mínima da população imunizada (menos de $2 \%$ das pessoas com duas doses da vacina) e com a disseminação acelerada de variantes do SARS-CoV-2 com maior poder de transmissão e, possivelmente, maior patogenicidade e letalidade. O prenúncio de um tsunami devastador sobre a população brasileira.

Dedicamos este Simpósio, respeitosamente, às vítimas da Covid-19 e seus familiares. E aos profissionais da saúde que incansável e ininterruptamente atendem pessoas acometidas pela doença.

Expressamos nossa enorme e profunda gratidão a cada um dos autores e autoras, professores e professoras, educadores e educadoras, especialistas em educação que reservaram uma parcela significativa do seu tempo para contribuir com este número especial da revista Medicina Ribeirão Preto.

Neste Simpósio, é possível reconhecer, compartilhar e admirar experiências de pessoas que lutaram e continuam lutando pela sobrevivência pessoal (em meio a pandemia), ao mesmo tempo que lutam pela sobrevivência de um valor muito maior, que nos une e dá sentido às nossas vidas, o ato de ensinar, facilitar aprendizagem, estimular a curiosidade e o desejo daqueles que desejam ir além e descobrirem o que ainda não Ihes é familiar. É isso que verdadeiros professores e professoras fazem. Trabalho nem sempre reconhecido, mas que jamais é esquecido por quem teve a oportunidade de experimentá-lo, na condição de aprendiz.

Faremos a seguir um breve tour apresentando, e esperando estimular a curiosidade e interesse dos leitores para os temas desenvolvidos, 
brilhantemente, pelos colaboradores deste Simpósio. Nossos colegas do Instituto de Biociências da Universidade de São Paulo (USP) iniciam o texto que produziram com a frase de Buddha, que é muito adequada para o momento que vivemos e seus impactos sobre nós:

"Não é a mudança, mas sim a resistência à mudança, que causa sofrimento"

E complementam...

"Adaptar-se não é fácil..." "...Contudo, em alguns momentos críticos, a mudança simplesmente nos atropela. Cabe a nós, então, aceitarmos essa mudança ou, inutilmente, lutarmos contra ela..."

O Professor Erick Bastos, do Instituto de Química da USP (IQ-USP), nos provoca e estimula com a seguinte observação:

"...o primeiro relato oficial de morte causada por COVID-19 ocorreu em janeiro de 2020 e, menos de um ano depois, mais de quarenta vacinas estão em teste e algumas já foram aprovadas para uso geral. Ter uma resposta tão rápida para uma crise global de saúde pública mostra a capacidade humana de entender problemas complexos e criar ferramentas para enfrentá-los.

Será que os meios que usamos para educar também têm se desenvolvido tão rapidamente ao longo do tempo?"

E complementa...

"Platão dava aulas cercado por oliveiras nos arredores de Atenas. Eu imagino que lousa e giz teriam revolucionado o ensino na Academia de Platão, mas essa tecnologia só foi criada cerca de 2.000 anos mais tarde."

O texto do professor Ewout Haar (Instituto de Física da USP), nos traz um relato histórico e conta uma pequena parcela da história do desenvolvimento das diversas plataformas de educação a distância que foram utilizadas na Universidade de São Paulo, até chegarmos ao atual e-Disciplinas e Moodle Extensão, que foi, sem dúvidas, o "bote salva-vidas da educação remota" na USP, após a decretação da pandemia da Covid-19.

Prof. Ewout nos responde a seguinte pergunta: "Como a USP chegou naquele momento (março de 2020), no início da pandemia, em uma condição bastante adequada e favorável para enfrentar a emergência global? A resposta a esta pergunta, é um belo relato sobre um projeto de proporções monumentais, que representa bem o que é a Universidade de São Paulo. Vale a pena conferir.

Em um artigo bastante provocativo, a especialista em educação, Danielle Benevenutto, discute o papel da universidade, seus professores e pesquisadores, no artigo intitulado: De seguidores de tendências à disrupção - uma lição (mal aprendida) que a ciência tem nos trazido há pelo menos um século.

Ela comenta, em um texto imperdível, o seguinte:

"...para que a Educação supere sua longa adolescência problemática com a exponencialidade dos avanços tecnológicos, é necessário que os seus operadores atuem de maneira proativa, passando da condição de meros seguidores de tendências a propositores de soluções, demandando, inclusive, as necessárias atualizações tecnológicas quando pertinentes."

No texto introdutório desse Simpósio, professores da Faculdade de Medicina de Ribeirão Preto (FMRP-USP), da Faculdade de Odontologia (FO-USP) e da Universidade Virtual do Estado de São Paulo (UNIVESP) abordam os princípios e boas práticas na educação presencial, educação remota ou a distância, ambiente virtual de aprendizagem, políticas institucionais, normas, regramento para educação a distância (EaD) e para a educação remota emergencial (ERE) nos tempos da pandemia.

Em um conjunto de textos produzidos pelos professores e membros do Centro de Desenvolvimento Docente para o Ensino (CDDE) da Faculdade de Medicina de Ribeirão Preto da Universidade de São Paulo (FMRP-USP) vários temas são discutidos e apresentam parte da experiência acumulada em 2020, nas várias ações direcionadas a apoiar os docentes da FMRP-USP na transição 
do ensino presencial para a ERE. Dentre os vários temas abordados destacamos: planejamento educacional, blueprint ou matriz curricular, desenho instrucional, estratégias de ensino e aprendizagem para ERE e EaD, avaliação do estudante e o papel do feedback na revisão da avaliação na pandemia, e finalmente como fazemos avaliação de programas educacionais. Cada um destes temas é discutido em um artigo na perspectiva da educação presencial e adaptações necessárias para a ERE e EaD.

Um dos textos merece destaque especial, por tratar da elaboração de um plano de ensino e aprendizagem (PEA), compartilhando a experiência da FMRP-USP em um esforço coletivo capitaneado pela Comissão de Graduação e o Centro de Apoio Educacional e Psicológico (CAEP) da faculdade. Os autores apresentam o PEA como algo mais do que apenas um documento a ser preenchido, ele "representa um momento importante de escolha, reflexão e de tomada de decisão para a formação dos sujeitos".

Vários textos deste Simpósio concluem que, a partir desta vivência educacional, não haverá mais espaço para modalidades singulares de ensino e aprendizagem, e que a educação e aprendizagem híbrida (blended-learning) deverá prevalecer para que melhores resultados em termos de ensino e aprendizagem sejam obtidos, beneficiando estudantes, professores e principalmente a sociedade que recebe os profissionais formados nos cursos superiores de todas as áreas do conhecimento.

Na sequência temos o prazer de conhecer experiências riquíssimas de várias instituições universitárias brasileiras. Desde o projeto ADESFIT, ou Aprimoramento Docente para o Ensino Superior da Fisioterapia da Universidade Federal de Minas Gerais (UFMG), que auxiliou professores a refletirem e enfrentarem o desafio de "aprender a ensinar" e "aprender e ensinar" no contexto da pandemia da Covid-19. Além de compreender como um programa de apoio ao docente organizado antes da pandemia foi a base de sustentação da resposta à pandemia na UFMG. Também nos apresenta o ADES-FIT Jr, que ampliou o olhar para as demandas e necessidades não apenas de professores, mas também de estudantes na capacitação para utilizarem re- cursos tecnológicos de forma efetiva. Uma experiência que merece ser conhecida.

Em outro artigo, conhecemos o trabalho que foi feito na Pontifícia Universidade Católica de São Paulo (PUC-SP), em especial nos cursos da Faculdade de Ciências Médicas e da Saúde, nos quais a situação crítica da pandemia e as reuniões virtuais, potencializaram o trabalho dos docentes do curso de Medicina para criar avaliações dos estudantes que valorizassem o raciocínio clínico e a interdisciplinaridade, em detrimento da simples memorização. Um exemplo claro de como, mesmo nos momentos de crise, há espaço para ganhos, há muito desejados, mas que puderam florescer na medida em que houve profunda mudança no processo de trabalho, catalizada pelo ERE.

No artigo intitulado, Desenvolvimento docente para educação remota emergencial: relato da Unicamp, temos a oportunidade de conhecer as ações da Universidade Estadual de Campinas que foram conduzidos pela Pró-Reitoria de Graduação para a formação docente na medida em que foi necessário migrar do ensino presencial para o ERE. Conhecemos qual foram os papéis e o suporte dado pelo Espaço de Apoio ao Ensino e Aprendizagem [EA] ${ }^{2}$ e do Grupo Gestor de Tecnologias Educacionais (GGTE) para os 69 cursos vinculados às áreas de Ciências Humanas; Artes; Ciências Biológicas e Profissões de Saúde e Exatas; e tecnológicas e da Terra, sediados nos campi de Campinas, Limeira e Piracicaba.

Finalmente, apresentamos a experiência do CDDE da FMRP-USP e os módulos criados para auxiliar professores nas práticas necessárias para - ERE. As ações foram moduladas, a partir da compreensão de que no início da pandemia, tínhamos entre os docentes, diferentes níveis de familiaridade com o ERE e, portanto, um espectro nas demandas por capacitação que exigiram maior diversidade de opções para atender as necessidades dos docentes. A partir desta compreensão, o CDDE apresenta um modelo de capacitação voltado a docentes mais iniciantes (pouco ou nenhum conhecimento/habilidade com o ERE), com alguma experiência prévia no uso da plataforma e-Disciplinas e no ERE, e aqueles que já tinham alguma expertise no tema. Estes últimos foram convidados a auxiliar nas oficinas, incluindo funcionários técnicos administrativos que fo- 
ram fundamentais para dar suporte aos docentes iniciantes, em estratégias "one-to-one", onde cada docente recebia suporte de um tutor para cumprimento de um programa mínimo e introdutório de capacitação.

Outro texto que merece atenção especial dos leitores é o que conta a história do "Pacto FMRP-USP por um semestre melhor: a pandemia passa e os laços ficam". Esta iniciativa, deu continuidade e ampliou uma campanha que havia começado antes da pandemia e tinha como mote central: FMRP- formado também melhores seres humanos, que destacava o papel da Universidade na formação de pessoas comprometidas com a excelência técnica, sem descuidar ou minimizar a importância dos princípios e valores que precisam acompanhar todos os profissionais da saúde.

Outro aspecto que permeia vários dos textos desse Simpósio, e merece destaque, é a existência, nas instituições representadas neste Simpósio, de centros, unidades ou iniciativas de apoio voltados ao desenvolvimento docente (algo como o que existe nas melhores universidades do mundo e que são denominados Centers for Teaching and Learning). Estes recursos instalados, foram decisivos e facilitadores para superação mais rápida e efetiva dos desafios impostos pela pandemia da Covid-19 ao ensino e avaliação. Vale mencionar que isto tudo aconteceu com nível menor de insegurança, sofrimento e retrabalho nas ações que foram implementadas.
Finalizamos o Simpósio com um texto que olha para o futuro, desafiando-nos a refletir e aprender com a experiência vivida durante a pandemia para compor novos cenários e possibilidades para a educação superior. Nele além de reafirmar nossa percepção de que o ensino híbrido deve nortear a revisão os processos educacionais no ensino superior, fazemos uma defesa enfática da manutenção das atividades de ensino prático presencial nos cursos da área da saúde, em todos os níveis, seguindo protocolos de segurança, mas reafirmando que a formação de profissionais da saúde é tão importante quanto o cuidado e atenção à saúde que deve ser oferecido às pessoas dele necessitam. A suspensão das atividades práticas não é um caminho, adaptá-las para que aconteçam com segurança para estudantes, professores e pacientes é o que devemos fazer.

Finalmente, parafraseando Milton Nascimento na canção nada será como antes (1976), ele nos diz:

... Resistindo na boca da noite um gosto de sol

Que nos dá conta da nossa dificuldade para reconhecer as necessidades de mudança e evolução. E acrescenta...

"Nada será como antes, amanhã"

Boa leitura a todos e todas!

Os Editores 